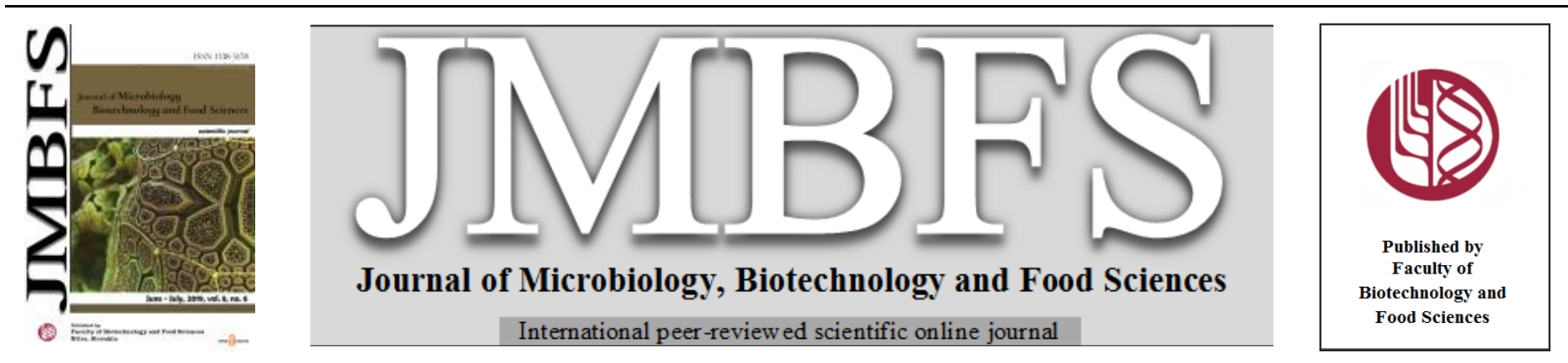

\title{
EVALUATION OF THE SYNERGISTIC EFFECT OF ETHANOL AND LEMONGRASS OIL AGAINST Aspergillus niger
}

\author{
Lieu My Dong*1, Dang Thi Kim Thuy ${ }^{2}$ \\ $\operatorname{Address(es):~}$ \\ ${ }^{1}$ Faculty of Food Technology, University of Food Industry, Ho Chi Minh City, Viet Nam, phone number: +84989961848 \\ 2 Institute of Tropical Biology, Ho Chi Minh City, Viet Nam.
}

*Corresponding author: lieudong289@gmail.com

doi: 10.15414/jmbfs.2019.8.6.1312-1316

ARTICLE INFO

Received 3. 8. 2018

Revised 6. 2. 2019

Accepted 8. 2. 2019

Published 1. 6. 2019

Regular article

open $\odot$ access

\begin{abstract}
The aim of this work was to evaluate the antifungal efficiency of ethanol and lemongrass oil at the different concentrations, alone and in combination both against Aspergillus niger by agar disk diffusion method, mycelial growth inhibition and broth dilution method to determine MIC and MFC. The ultraviolet (UV) absorption and electrical conductivity of the culture supernatant were used to determine membrane integrity. Scanning electron microscopy (SEM) performed to observe A. niger spore morphology. The results showed that the MIC and MFC values of lemongrass oil (in tween $200.3 \% \mathrm{v} / \mathrm{v}$ ) was $5 \mu \mathrm{L} / \mathrm{mL}$ and $250 \mathrm{ppm}$ which were 100 and 200 times respectively lower than ethanol. The combination of lemongrass oil in tween 20 with ethanol $(20 \% \mathrm{v} / \mathrm{v})$ show the best result with the inhibition zone and MGI (\%) was observed at $2.5 \mu \mathrm{L} / \mathrm{mL}$ and $100 \%$ respectively. The UV absorption and electrical conductivity values increased quickly after $16 \mathrm{~h}$ incubated in the antimicrobial agents whereas there were almost unchanged in the control at the point of time. The SEM results show that, the morphological changes of the A. niger spores due to significant wrinkles and distortion in the samples treated by lemongrass oil or lemongrass oil combining with ethanol while the A. niger spores in ethanol show slight wrinkles. These suggest that ethanol has a synergic effect which enhances the antifungal activity of lemongrass oil. This combination is necessary to ensure the antimicrobial effect as well as reduce the amount of used essential oil.
\end{abstract}

Keywords: Ethanol, lemongrass oil, antifungal activity, SEM, synergistic effect, tween 20

\section{INTRODUCTION}

Post-harvest losses are one of the major causes of the loss of fresh vegetables during the supply chain (Nunes et al., 2012). Aspergillus niger is one of the major causes of black rot of plain (Prakash et al., 1988). Therefore, control of $A$. niger during the preservation is very necessary. The widespread use of synthetic fungicides for preserving agricultural products has significant limitations such as handling of hazards, pesticide residues, and risk to health and the environment (Dharini et al., 2014). Current trends in antimicrobial agent research from the natural origin in which plant-derived essential oils are of great interest. In previous studies, lemongrass oil is considered an essential oil for safe and effective natural preservatives which has an effective antibacterial activity (Vazirian et al., 2012). Essential oils are natural products consisting of a complex mixture of volatile molecules (Mahian et al., 2016), which are liquid, soluble in organic solvents and insoluble in water (Bakkali et al., 2008). The evaluation of the antimicrobial activity, the essential oils are often diluted at different concentrations by emulsifying agents (Burt, 2004). Hilbig et al. (2016) reported that emulsifier has the negative effect on the antimicrobial activity of essential oil (Hilbig, 2016), whereas the combination of ethanol and other antimicrobial agents (chitosan, potassium sorbate ...) show the antimicrobial activity better than using in single agent (Romanazzi $\boldsymbol{e t}$ al., 2007; Karabulut $\boldsymbol{e}$ al., 2005). Besides essential oil, ethanol also showed antimicrobial effect (Gianfranco et al., 2007). However, to achieve good antibacterial efficacy, ethanol is commonly used at high concentrations leading to increased production costs and the risk of fire safety (Ozgur et al., 2005). Ethanol is made up of hydrophilic $(-\mathrm{OH})$ and hydrophobic $\left(\mathrm{CH}_{3} \mathrm{CH}_{2}-\right)$ radicals. Hydrophilic radicals ($\mathrm{OH})$ to help dissolve the polarizing elements and ions. Short chain $\mathrm{CH}_{3} \mathrm{CH}_{2-}$ hydrocarbons can attract non-polar molecules. Therefore, the combination of ethanol and essential oil can both increase the dilution effect of the oil in the media and can synergize with the essential oil to enhance the effectiveness of the antimicrobial. Although the combination of ethanol and the essential oil is very promising, very few studies exist on the synergic effect of ethanol and lemongrass oil on fungi. In this study, the antifungal activity of lemongrass oil and ethanol used alone or in combination against $A$. niger was evaluated by agar disk diffusion method, mycelial growth inhibition and broth dilution method to determinate MIC and MFC. The ultraviolet (UV) absorption and electrical conductivity of the culture supernatant were used to determine membrane integrity. Scanning electron microscopy (SEM) performed to observe the morphology of Aspergillus niger spores.

\section{MATERIAL AND METHODS}

\section{Materials}

Aspergillus niger M1 was obtained from strain collection of Faculty of Food Technology, Ho Chi Minh City University of Food Industry. A. niger was grown in PDA (Potato Dextrose Agar) medium at $30^{\circ} \mathrm{C}$ for 6 days. Then, the mass was harvested by rinsing plates with PDB (Potato Dextrose Broth). The freshly grown microbial cell at approximately $6 \log \mathrm{CFU} / \mathrm{mL}$ was used for the evaluation of the antifungal activity.

The essential oil in this study was lemongrass oil (Cymbopogon flexuosus) from Tien Giang province, the City is located at $10^{\circ} 25^{\prime} \mathrm{N} 106^{\circ} 10^{\prime} \mathrm{E}$ in the southern region of Vietnam. Lemongrass was hand-collected and immediately used to obtain lemongrass oil by steam distillation. Lemongrass oil was stored in glass vials in the absence of light until gas chromatography analysis and to test its antifungal activity. The essential oil was directly analyzed by gas chromatography coupled to mass spectrometry (Agilent GC 7890B GC System, 7010 GC/MS Triple Quad). The used column was an HP-5MS (30 m long, 0.25 $\mathrm{mm}$ and $0.25 \mu \mathrm{m}$ film thickness). The operating conditions were as follows: Helium was used as a carrier gas with a back pressure of $0.8 \mathrm{~atm}$; flow rate of 1.0 $\mathrm{mL} / \mathrm{min}$; split 1:20; injection volume $0.2 \mu \mathrm{L}$; The injector temperature was $250^{\circ} \mathrm{C}$ and the oven temperature program started at 60 for $5 \mathrm{~min}$ and then increased at the rate of $5^{\circ} \mathrm{C} / \mathrm{min}$ up to $150^{\circ} \mathrm{C}$ at $5^{\circ} \mathrm{C} / \mathrm{min}$, and increased from $150^{\circ} \mathrm{C}$ to $280^{\circ} \mathrm{C}$ at $10^{\circ} \mathrm{C} / \mathrm{min}$. The constituents in the essential oils were identified by computer matching of their mass spectral fragmentation patterns with those of compounds in the data bank NIST 98 and Wiley 275 library. Lemongrass oil and ethanol used alone or in combination with or without tween $20(0.3 \%$ v/v) (an emulsifying agent) were used as antifungal agents for the next step. 
Evaluation of antifungal activity of lemongrass oil and ethanol used alone or in combination against $A$. niger

\section{Diffusion method}

The antifungal activity of lemongrass oil and ethanol was carried out according to Lieu et al. (2018a) with slight modifications. Briefly, the A. niger suspensions were spread over the surface of PDA (Potato Dextrose Agar) plates (at final concentration $6 \log \mathrm{CFU} / \mathrm{mL}$ approximately) and allowed to dry in $5 \mathrm{~min}$ Lemongrass oil $(10 ; 20 ; 40 ; 80$ and $100 \mu \mathrm{L} / \mathrm{mL})$ and ethanol $(10 \% ; 20 \% ; 40 \%$; $80 \%$ and $100 \% \mathrm{v} / \mathrm{v})$, used alone or in combination with or without tween $200.3 \%$ $\mathrm{v} / \mathrm{v}$ (an emulsifying agent) were spotted on PDA agar $(15 \mu \mathrm{L})$, that containing $A$ niger spores and tween 20 were used as controls. The plates were incubated at $30^{\circ} \mathrm{C}$ in 24 hours. After $24 \mathrm{~h}$ incubated, Petri dishes were examined by inhibition zone.

\section{Determination of the antifungal effect of lemongrass oil and ethanol on mycelial growth}

The effect of emulsifying agents to antifungal activity of lemongrass oil on mycelial growth was carried out as assay previously described (Boubaker $\boldsymbol{e t}$ al., 2016) with slight modifications. Briefly, PDA supplemented individually with antifungal agents such as lemongrass oil; ethanol and the combination of lemongrass oil with ethanol. The mixture was poured into Petri plates. Afterward, the Petri plates were incubated with A. niger by spore culture at the middle of the Petri plates. The agar Petri plates were then incubated at $30^{\circ} \mathrm{C}$ in seven days. The control consisted of PDA medium supplemented with emulsifying agents withou lemongrass oil. The antifungal activity was expressed in terms of percentage of mycelial growth inhibition (MGI) and calculated according to the following formula:

MGI $(\%)=(\mathrm{C}-\mathrm{T}) / \mathrm{C} \times 100 \%$

Where $\mathrm{C}$ and $\mathrm{T}$ represent mycelial growth diameter in control and lemongrass oil treated Petri plates, respectively

\section{Determination of MFC Using Broth Dilution Method}

Minimum fungicidal concentration (MFC) of lemongrass oil and ethanol were carried out according to the previous description (Lieu et al., 2018a). A range of lemongrass oil $(100 \div 1,000 \mu \mathrm{L} / \mathrm{L}$ in tween $200.3 \% \mathrm{v} / \mathrm{v})$ and ethanol $(10,000 \div 100,000 \mu \mathrm{L} / \mathrm{L})$ concentrations use alone or in combination were prepared in PDB (Potato Dextrose broth) medium. Each flask was inoculated with $6 \log \mathrm{CFU} / \mathrm{mL}$ of the A. niger spores. Flasks containing only tween 20 (without lemongrass oil) were used as the control. The flasks were incubated at $30^{\circ} \mathrm{C}$ in an orbital shaking incubator $(100 \mathrm{rpm})$ for $48 \mathrm{~h}$. One $\mathrm{mL}$ of culture was taken from each flask (where growth was not observed) for serial dilution to make the inoculum of $6 \log \mathrm{CFU} / \mathrm{mL}$ and inoculated on DRBC (Dichloran Rose Bengal Chloramphenicol) agar plates at $30^{\circ} \mathrm{C}$ in three days

\section{UV absorption and conductivity determination}

The experiments were conducted based on a previously published method (Suxia et al., 2015) with slight modifications (adding the equation). Briefly, the spore of A. niger diluted to the test concentration by optical density (at final concentration $6 \log$ CFU/mL approximately) and separated into several flasks. The lemongrass oil and ethanol used alone or in combination at MFCs were added to each flask, except to the control and incubated at $30^{\circ} \mathrm{C}$. During incubation time, $15 \mathrm{~mL}$ sample was removed from the flasks at $0,2,4,6,8,19,12,14$ and 16 hours of incubation. The samples were immediately filtered using $0.22 \mu \mathrm{m}$ syringe filters to remove bacteria and recorded by spectrophotometer at $260 \mathrm{~nm}$ and by the conductivity meter. The effect of antifungal agents to the leakage of cytoplasmic contents was evaluated by the following equation:

$$
\delta_{D D}=O D_{L}-O D_{0}
$$

$\delta_{\mathrm{OD}}$ : delta values of UV absorption

$\mathrm{OD}_{\mathrm{t}}$ : OD value at $\mathrm{t}$ time

$\mathrm{OD}_{0}$ : Initial OD value

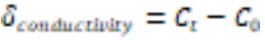

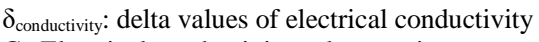

$\mathrm{C}_{\mathrm{t}}$ : Electrical conductivity value at $\mathrm{t}$ time

$\mathrm{C}_{0}$ : Electrical initial conductivity value.

The treated and untreated samples after $8 \mathrm{~h}$ of incubation were observed through the Scanning Electron Microscope (SEM) to evaluate the effect of antifungal agents to the spore of $A$. niger.

\section{Statistical analysis}

The data were subjected to analysis of variance (ANOVA) using SigmaPlot 11 followed by Student-Newman-Keuls t-test to compare means, with a significance level of $5 \%$ when the significant difference between treatments was noted. All tests were performed in triplicate and the data expressed as means \pm standard deviation.

\section{RESULTS}

\section{The chemical composition of the lemongrass oil}

Major components of lemongrass oil were confirmed and listed in Table 1. $\beta$ citral was identified as the main compound with the highest peak area percentage (41.2\%). $\alpha$-citral $(39.80 \%)$ was the second major compound detected in the lemongrass oil, followed by Neryl acetate (8.1\%); Caryophyllene $(1.5 \%)$, Linalool (1.5\%), Caryophyllene oxide (1.1\%). Other compounds such as Verbenol, Carveol, Eucalyptol ... were found to be at the trace level.

Table 1 Major components of lemongrass oil

\begin{tabular}{ll}
\hline Components & $\boldsymbol{\%}^{*}$ \\
\hline$\beta$-Citral & 41.2 \\
\hline$\alpha$-Citral & 39.8 \\
\hline Camphene & 0.3 \\
\hline 5-Hepten-2-one, 6-methyl- & 1.5 \\
\hline Limonene & 0.2 \\
\hline Eucalyptol & 0.5 \\
\hline Linalool & 1.5 \\
\hline Citronellal & 0.3 \\
\hline Verbenol & 0.6 \\
\hline Carveol & 1.0 \\
\hline Neryl acetate & 8.1 \\
\hline Caryophyllene & 1.5 \\
\hline Caryophyllene oxide & 1.1 \\
\hline
\end{tabular}

"Percent of the peak area of the evaporated organic compound

Antifungal activity of essential oils and ethanol in the agar diffusion method

The antifungal activity of lemongrass oil and ethanol were shown in Figure 1 and 2 . The antifungal zone depends on the concentration of antifungal agents and their combination. The diameter of the antifungal zone of lemongrass oil, ethanol, and their combination was $4.67 \div 21 \mathrm{~mm} ; 4.67 \div 10 \mathrm{~mm}$ and $4 \div 29 \mathrm{~mm}$ respectively (Figure 1).
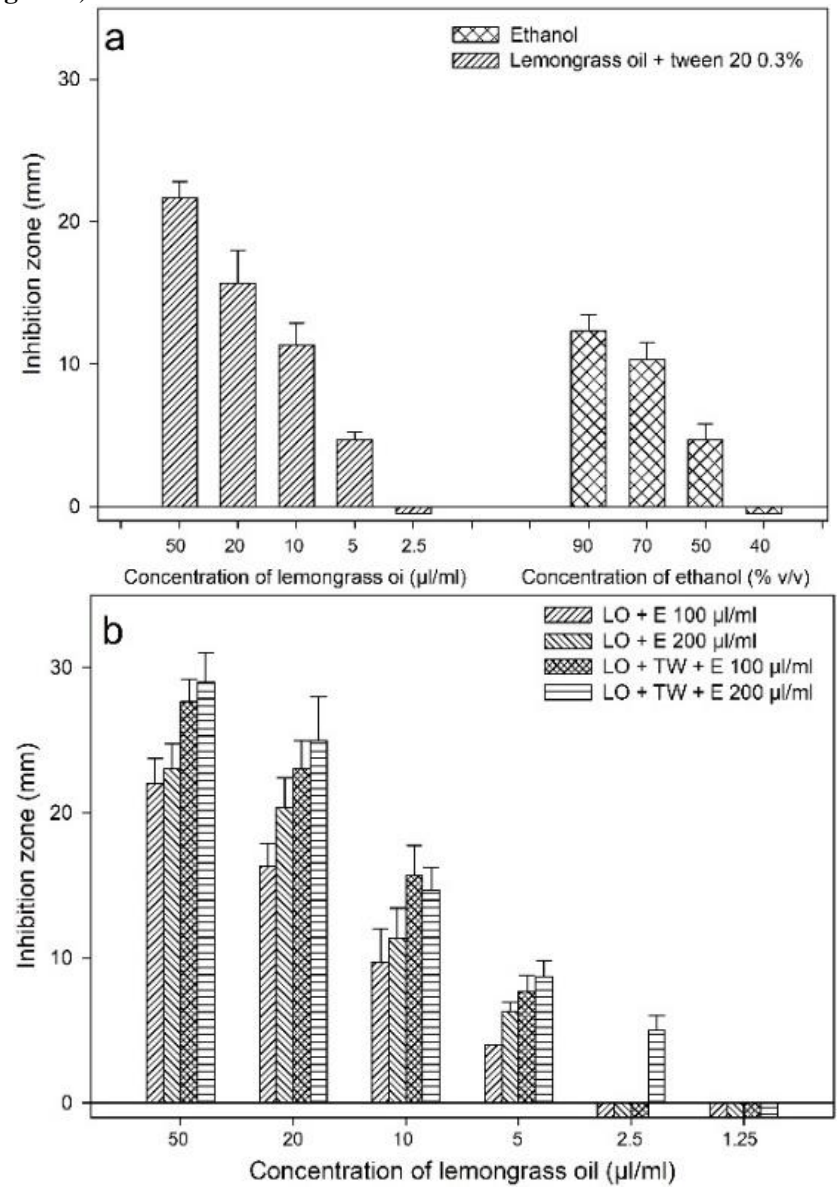

Figure 1 The impact of lemongrass oil and ethanol used alone (a) or in combination (b) against $A$. niger (LO: lemongrass oil; E: ethanol; TW: tween 20) 


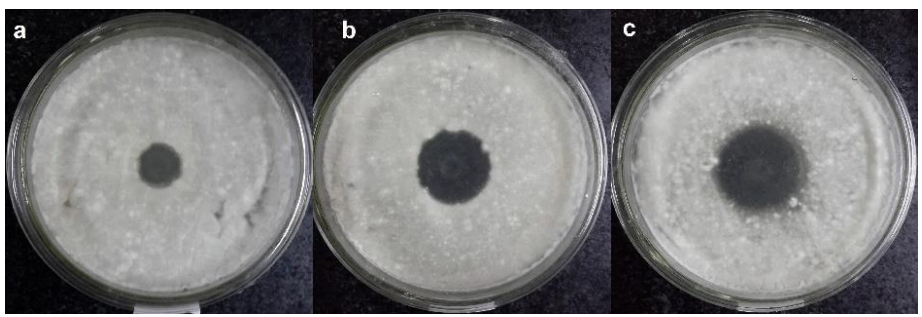

Figure 2 The diameter of the antifungal zone of ethanol 90\% v/v (a), lemongrass oil $50 \mu \mathrm{L} / \mathrm{mL}$ in tween 20 (b) and the combination of lemongrass oil $(50 \mu \mathrm{L} / \mathrm{mL})$ and ethanol $(100 \mu \mathrm{L} / \mathrm{mL})$ in tween 20 (c).

In case of alone treatments, lemongrass oil (in tween 20) showed more antimicrobial effect than ethanol with the minimum inhibitory concentration (MIC) was $5 \mu \mathrm{L} / \mathrm{mL}$, while the MIC values of ethanol was $500 \mu \mathrm{L} / \mathrm{mL}(50 \% \mathrm{v} / \mathrm{v})$ which was 100 times higher than the lemongrass oil. The result in case of combined treatments showed that the antimicrobial activity of the lemongrass oil in tween 20 was no significant different $(p>0.05)$ with the lemongrass oil (without tween 20) in ethanol (Figure 1). The inhibition zone diameter of the combination of lemongrass oil (in tween 20) with ethanol (10\%) were higher than these lemongrass oils and ethanol at the same concentration, but the MIC value of the combination of lemongrass oil with ethanol (10\%) was not different compared to lemongrass oil that using alone. However, the combination of lemongrass oil in tween 20 with ethanol (20\% v/v) show the best result (Figure 1, 2). The MIC value of this combination was at $2.5 \mu \mathrm{L} / \mathrm{mL}$.

\section{Effects of lemongrass oil and ethanol on Mycelial Growth}

The effects of lemongrass oil and ethanol on A. niger mycelial growth are shown in Figure 3. The results showed that, after five days of incubation, the colony diameter of $A$. niger in control sample was $90 \mathrm{~mm}$ while in the treatment samples, the colony diameter of $A$. niger was decreased significantly through the MGI (\%) values. In case of alone treatment, the MGIs (\%) of ethanol at 10,000 ; 20,000 and $50,000 \mathrm{ppm}$ were $1.11 \% ; 63.33 \%$ and $50.33 \%$. The MGIs $(\%)$ of lemongrass oil (in tween $200.3 \% \mathrm{v} / \mathrm{v}$ ) and the combination of lemongrass oi with ethanol $10,000 \mathrm{ppm}$ or $20,000 \mathrm{ppm}$ at 150 and $300 \mathrm{ppm}$ of concentration were $67.22 \%$ and $83.89 \% ; 58.33 \%$ and $73.89 \% ; 62.22 \%$ and $82.22 \%$ respectively (Figure 3).

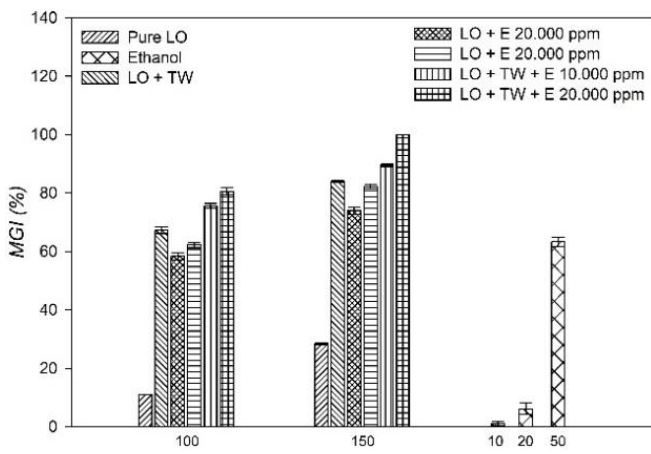

Figure 3 Effect of lemongrass oil and ethanol used alone or in combination on mycelial growth of $A$. niger (LO: lemongrass oil; E: ethanol; TW: tween 20)

The combination of lemongrass oil (in tween $200.3 \% \mathrm{v} / \mathrm{v}$ ) with ethanol 20,000 ppm showed the best result that the MGI (\%) was $100 \%$. The results showed that the MGIs (\%) of lemongrass oil were significantly higher than ethanol. The combination of lemongrass oil (in tween 20) with ethanol is necessary to enhance the antifungal activity.

\section{Antifungal activity of essential oils in the liquid phase}

According to the results obtained (Table 2), the MFC values of lemongrass oi and ethanol has the same result as that observed in the agar diffusion test. In case of alone treatments, the MFC values of lemongrass oil (in tween $200.3 \% \mathrm{v} / \mathrm{v}$ ) was $250 \mathrm{ppm}$ which has 200 times lower than ethanol that needs to increase the concentration to 50,000 ppm to reach the same result (Table 2).

Table 2 MFCs value of lemongrass oil and ethanol

\begin{tabular}{ll}
\hline Antifungal agents & MFC (ppm) \\
\hline Lemongrass oil & 450 \\
\hline Ethanol & 50,000 \\
\hline Lemongrass oil + ethanol 1\% & 280 \\
\hline Lemongrass oil + ethanol 2\% & 250 \\
\hline Lemongrass oil + tween $0.3 \%$ & 250 \\
\hline Lemongrass oil + tween $0.3 \%+$ ethanol 1\% & 180 \\
\hline Lemongrass oil + tween $0.3 \%+$ ethanol 2\% & 150 \\
\hline
\end{tabular}


result also observed in the lemongrass oil $(150 \mathrm{ppm})$ in tween 20 combined with ethanol (20\% v/v) (Figure 5c).

\section{DISCUSSION}

Control of A. niger during the preservation is necessary because of their effect caused to post-harvest losses (Prakash et al., 1988; Lieu et al., 2018b). Plain essential oils are gaining interest in their antimicrobial activity. Due to the components of essential oil depending on the variety of plant, the part of the plant considered, harvesting seasons, storage conditions, the concentration of essential oil... as well as the type of tested microorganism (Burt et al., 2004; Tajkarimi et al., 2010, Tyagi et al., 2010; Lieu et al., 2018a), which make it difficult to compare results across laboratories. It is well-known that essential oil affects bacterial cells by many different mechanisms such as the following: disrupt the phospholipid bilayer of the cell membrane; break down the phospholipid membrane which leading to structural breaking, affecting the integrity of cell membranes and changing the permeability of $\mathrm{H}^{+}$and $\mathrm{K}^{+}$ions (Dinesh et al., 2013; Dharini et al., 2014). The lemongrass oil with monoterpenes is formed by $\alpha$-citral and $\beta$-citral that the main antimicrobial activity, which showed an inhibitory effect and causing distortion of cytoplasmic membranes of Candida albicans (Tyagi et al., 2010). Similarly, the antimicrobial action of ethanol, which able to penetrate the cell wall, causing protein degradation, lipid dissolution, and finally cellular breakage (Weber et al., 1996).

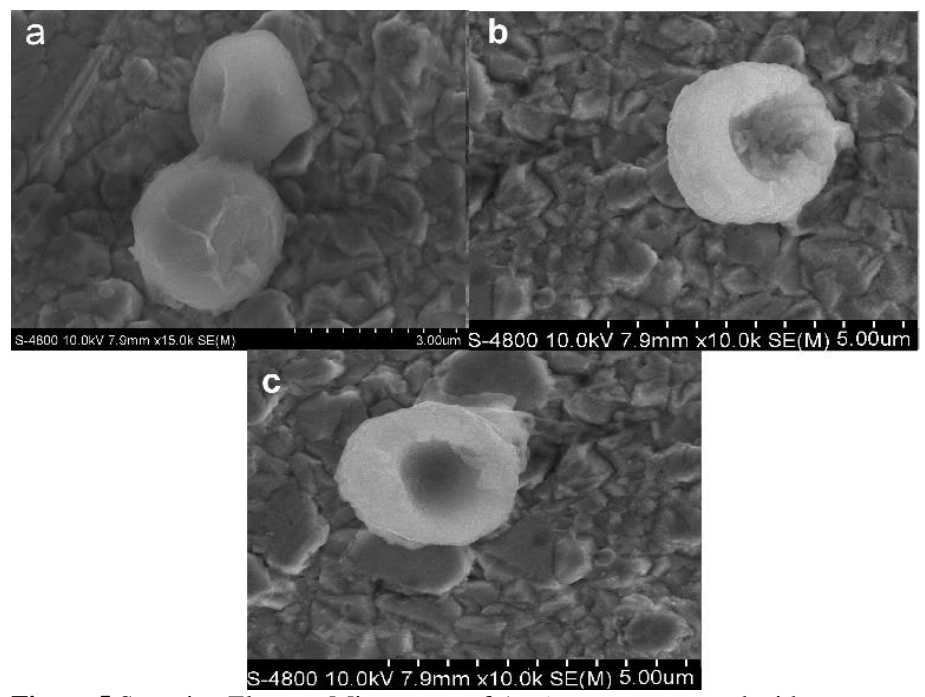

Figure 5 Scanning Electron Microscope of $A$. niger spores treated with lemongrass and ethanol. a. A. niger spores were grown in the presence of ethanol $50,000 \mathrm{ppm}$; b. A. niger spores grown in the presence of lemongrass oil (in tween 20) $250 \mathrm{ppm}$; c. A. niger spores grown in the presence of the combination of lemongrass oil (in tween 20) $150 \mathrm{ppm}$ and ethanol 20,000 ppm.

In previous studies, ethanol $(20 \% \mathrm{v} / \mathrm{v})$ showed the ability to reduce the spore growth of Botrytis cinerea compared to the control (Ozgur et al., 2005) as well as to reduce the grape damage caused by Botrytis cinerea, while the combination of ethanol and chitosan is necessary to control fungi effectively (Gianfranco $\boldsymbol{e}$ al., 2007). In the present study indicates that ethanol shows the antifungal activity against $A$. niger at $500 \mu \mathrm{L} / \mathrm{mL}$ in the agar diffusion test and 50,000 ppm in MFC test which has 100 times and 200 times higher than lemongrass oil $(5 \mu \mathrm{L} / \mathrm{mL}$ and $250 \mathrm{ppm}$ respectively) (Figure 1 and Table 2). These suggest that lemongrass oil was more effective at inhibiting A. niger than ethanol. The differences in the antimicrobial concentration of essential oil in agar diffusion tests and broth dilution assays were reported in previous studies (Boubaker et al., 2016; Lieu et al., 2018a). The differences are due to the type of media, the ability to dilute the essential oil of emulsifiers. Verica et al. (2014) reported that the agar diffusion method is not considered an ideal method for essential oil dilution, because of their volatile and poorly soluble components. This makes the essential oil in the agar diffusion method is required high concentration than broth dilution method to have the equivalent antimicrobial effect (Figure 1 and Table 2). In the MFC assays, pure lemongrass oil showed the lowest antifungal activity (Table 2). Water is not an effective method for dispersing the essential oil due to the insoluble phenolic compounds, leading to a decrease in the antimicrobial activity of essential oil (Laird, 2011). Therefore, the emulsifying agent is necessary to enhance antifungal activity.

Due to hydrophobic properties, high volatility and flavoring properties of essential oil which could affect the organoleptic quality of food, the essential oil needs to dilute to required concentrations to ensure sufficient antimicrobial effect without affecting the organoleptic properties of the food. In previous studies, the essential oil was usually diluted in emulsifier such as tween 80, tween 20 , xanthan gum (Boubaker et al., 2016; Lieu et al., 2018a,b) or other antimicrobia agents (Ghellai et al., 2015) to enhance the solubility of essential oil and reduce the amount of essential oil needed to use. The combination of essential oil $0.5 \%$ $(\mathrm{v} / \mathrm{v})$ with acetic acid $0.25 \%(\mathrm{v} / \mathrm{v})$ and lactic acid $0.25 \%(\mathrm{v} / \mathrm{v})$ showed the antimicrobial effect was equivalent to essential oil 1\% (v/v) (Ghellai et al., 2015). However, the combination of essential oil (in the emulsifying agent) and ethanol is poorly reported. The solubility of lemongrass in tween 20 is better than ethanol (data not showed). The antifungal activity of the combination of lemongrass oil (in tween 20) and ethanol was improved significantly (Figure 1, 2, 3, 4). This finding suggests that ethanol has a synergistic effect which enhances the antimicrobial activity of lemongrass oil. Meanwhile, tween 20 helps to disperse the essential oil in the water phase and increasing the antimicrobial activity. The combination of lemongrass oil and ethanol showed the antimicrobial activity increase when increasing the ethanol concentration (over $20 \% \mathrm{v} / \mathrm{v}$ ) (data not showed). However, the use of ethanol at high concentration in agricultural product preservation would raise costs and the risk of un-safety (Ozgur $\boldsymbol{e t}$ al., 2005). In the present study, the combination of lemongrass oil, tween $20(0.3 \%$ $\mathrm{v} / \mathrm{v}$ ) and ethanol showed the best result which not only minimizes the amount of essential oil but also ensures the antimicrobial activity.

The use of UV absorption assay, an electrical conductivity test, and SEM observation are considered an effective way to evaluate the antifungal effect of antifungal agents. In the previous study, the SEM results showed that, at concentration of $0.5 \mu \mathrm{L} / \mathrm{mL}$, lemongrass caused swelling of the cell wall and much of the cell contents in many bacteria were lost when increasing to $2 \mu \mathrm{L} / \mathrm{mL}$ (Jareerat et al., 2011). The antimicrobial components of lemongrass oil can cause yeast deformation or bacterial membrane deformation, leading to leakage of cellular contents (Tyagi $\boldsymbol{e t}$ al., 2010; Jareerat $\boldsymbol{e t}$ al., 2011). In the present study, the initial absorbance values and electrical conductivity of the samples treated with antimicrobial agents are much different, this is due to the antimicrobial agents caused different absorbance. However, the Figure 4 shows that the UV absorption values and electrical conductivity values in the samples treated by antimicrobial agents that without A. niger were almost unchanged at the point of time $(0 \mathrm{~h}, 2 \mathrm{~h}, 4 \mathrm{~h}, 6 \mathrm{~h}, 8 \mathrm{~h}, 10 \mathrm{~h}, 12 \mathrm{~h}, 14 \mathrm{~h}$, and $16 \mathrm{~h})$. These results indicated that the concentration of antimicrobial agents does not affect the changes in absorbance values and electrical conductivity of the culture medium during the experiment. It is interesting to note that, the delta value and SEM result in the combination of lemongrass oil $(150 \mathrm{ppm})$ in tween $200.3 \% \mathrm{v} / \mathrm{v}$ and ethanol 20,000 ppm were no significant difference compared to lemongrass oil $250 \mathrm{ppm}$ in tween $20(0.3 \% \mathrm{v} / \mathrm{v})$ which $40 \%$ higher than that lemongrass oil in the combination treatment. These data suggest that ethanol has a synergic effect which enhances the antifungal activity of lemongrass oil. This combination is necessary to ensure the antimicrobial effect as well as reduce the amount of used essential oil.

\section{CONCLUSION}

The results indicated that the MIC and MFC values of lemongrass oil (in tween $200.3 \% \mathrm{v} / \mathrm{v}$ ) were $5 \mu \mathrm{L} / \mathrm{mL}$ and $250 \mathrm{ppm}$ respectively that 100 and 200 times lower than ethanol. The antifungal effect of the combination of ethanol and lemongrass oil against $A$. niger showed better results than used alone. The combination of lemongrass oil (in tween 20$)$ and ethanol $(20 \% \mathrm{v} / \mathrm{v})$ with the inhibition zone and MGI (\%) value was at $2.5 \mu \mathrm{L} / \mathrm{mL}$ and $100 \%$ respectively that showed the best result. The UV absorption and electrical conductivity values increased quickly during incubated in the antifungal agents, whereas there were almost unchanged in the control samples at the point of time. The SEM results show that the morphological changes of the A. niger spores due to ethano $(50,000 \mathrm{ppm})$ treatment showed slight wrinkles whereas, in the samples treated by lemongrass oil or lemongrass oil combining with ethanol, A. niger spores were significant wrinkles and distortion. The results showed that ethanol and tween 20 enhanced the antifungal activity of lemongrass oil at low concentration in which the combination of lemongrass oil (in tween 20) and ethanol showed the best results. This combination is necessary to ensure the antimicrobial effect as well as reduce the amount of used essential oil.

\section{REFERENCES}

Bakkali, F., S. Averbeck, D. Averbeck, M. Idaomar. "Biological effects of essential oils - A review." Food and Chemical Toxicology 46, 2008: 446-475. https://doi.org/10.1016/j.fct.2007.09.106

Boubaker. H, Karim. H, El Hamdaoui. A, Msanda. F, Leach. D, Bombarda. I, Vanloot. P, Abbad. A, Boudyach. E. H, Ait Ben Aoumar. 2016. Chemical characterization and antifungal activities of four Thymusspecies essential oils against postharvest fungal pathogens of citrus, Industrial Crops and Products. 86: 95-101. https://doi.org/10.1016/j.indcrop.2016.03.036

Burt, S. Essential oils: their antibacterial properties and potential applications in foods-a review. International Journal of Food Microbiology, 94, 2004: 233 253. https://doi.org/10.1016/j.ijfoodmicro.2004.03.022

Dharini Sivakumar, Silvia Bautista-Banos., A review on the use of essential oils for postharvest decay control and maintenance of fruit quality during storage Crop Protection 64 (2014) 27-37. https://doi.org/10.1016/j.cropro.2014.05.012 
Dinesh D. Jayasena and Cheorun Jo. 2013. Essential oils as potential antimicrobial agents in meat and meat products: A review. Trends in Food Science \& Technology. 34: 96-108. https://doi.org/10.1016/j.tifs.2013.09.002

Ghellai, L. and Y. Beral. Antibacterial efficacy of essential oil of Thymus capitatus, lactic acid and acetic acid against Escherichia coli in craw chicken meat. International Journal of Advanced Multidisciplinary Research, 2015: 4247.

Gianfranco Romanazzi, Ozgur A. Karabulut, Joseph L. Smilanick. Combination of chitosan and ethanol to control postharvest gray mold of table grapes, Postharvest Biology and Technology 45 (2007) 134-140. https://doi.org/10.1016/j.postharvbio.2007.01.004

Hilbig, J., Q. Ma, P. M. Davidson, J. Weiss and Q. Zhong. Physical and antimicrobial properties of cinnamon bark oil co-nanoemulsified by lauric arginate and Tween 80. International Journal of Food Microbiology, 233, 2016 52-59. https://doi.org/10.1016/j.ijfoodmicro.2016.06.016

Jareerat Aiemsaard, Suneerat Aiumlamai, Chantana Aromdee, Suwimol Taweechaisupapong, Watcharee Khunkitti., 2011. The effect of lemongrass oil and its major components on clinical isolate mastitis pathogens and their mechanisms of action on Staphylococcus aureus DMST 4745. Research in Veterinary Science 91, 31-37. https://doi.org/10.1016/j.rvsc.2011.01.012

Karabulut, O. A., G. Romanazzi, J. L. Smilanick and A. Lichter. Postharvest ethanol and potassium sorbate treatments of table grapes to control gray mold. Postharvest Biology and Technology, 37, 2005: 129-134. https://doi.org/10.1016/j.postharvbio.2005.04.001

Lieu, Dong M., Thuy TK Dang, and Huong T. Nguyen. Enhance the antimicroorganism activity of cinnamon oil by xanthan gum as emulsifying agent. In AIP Conference Proceedings, vol. 1954, no. 1, p. 040017. AIP Publishing, 2018a. https://doi.org/10.1063/1.5033417

Lieu, M. D., Ngo, N. N. H., Lieu, T. L., Nguyen, K. T., \& Dang, T. K. T. The efficacy of combined application of edible coatings and essential oi in mango preservation. Vietnam Journal of Science and Technology, 56(4) (2018b), 458 https://doi.org/10.15625/2525-2518/56/4/10794

Mahian, R. A. and A. M. Sani. Essential oils in Food Systems: A systemic review. International journal of PharmTech research, 6, 2016: 409-416.

Nunes, Carla Alexandra. - Biological control of postharvest diseases of fruit, $E u r$ $\begin{array}{llll}J & \text { Plant } \quad \text { Pathol, } & 133 & \text { (2012) }\end{array}$ https://doi.org/10.1146/annurev.phyto.40.120401.130158

Ozgur Akgun Karabulut, Gianfranco Romanazzi, Joseph L. Smilanick, Amnon Lichter. Postharvest ethanol and potassium sorbate treatments of table grapes to control gray mold. Postharvest Biology and Technology 37 (2005): 129-134. https://doi.org/10.1016/j.postharvbio.2005.04.001

Prakash, O., and M.A. Raoof. - Control of mango fruit decay with post harvest application of various chemicals against black rot, stem end rot and anthracnose disease, International Journal of Tropical Plant Diseases 6 (1988) 99-105.

Romanazzi, G, O. A. Karabulut and J. L. Smilanick. Combination of chitosan and ethanol to control postharvest gray mold of table grapes. Postharvest Biology and Technology (45), 2007: 134-140. https://doi.org/10.1016/j.postharvbio.2007.01.004

Tajkarimi, M. M., Ibrahim, S. A., and Cliver, D. O. 2010. Antimicrobial herb and spice compounds in food. Food Control. 21: 1199-1218. https://doi.org/10.1016/j.foodcont.2010.02.003

Tyagi, A K, Malik A (2010). Liquid and vapour-phase antifungal activities of selected essential oils against Candida albicans: microscopic observations and chemical characterization of Cymbopogon citratus. BMC Complement Altern Med, 10(1), 65. https://doi.org/10.1186/1472-6882-10-65

Vazirian, M, M. R. S. Ardekani, M. Khavani, H. Jamalifar, M. R. Fazeli, A. N. Toosi and S. T. Kashani. Antimicrobial activity of lemongrass (Cymbopogon citratus (DC) Stapf.) essential oil against food-borne pathogens added to creamfilled cakes and pastries. The Journal of Essential Oil Research 24 (6), 2012 579-582. https://doi.org/10.1080/10412905.2012.729920

Verica Aleksic, Petar Knezevic. 2014. Antimicrobial and antioxidative activity of extracts and essential oils of Myrtus communis L. Microbiological Research 169: 240-254. https://doi.org/10.1016/j.micres.2013.10.003

Weber FJ and de Bont JA. 1996. Adaptation mechanisms of microorganisms to the toxic effects of organic solvents on membranes. Biochim Biophys Acta 1286(3):225-45. https://doi.org/10.1016/S0304-4157(96)00010-X 